\title{
Síndrome de Erasmus (exposição à sílica e esclerose sistémica): um caso clínico
}

\section{Erasmus Syndrome (exposure to silica and systemic sclerosis): a case report.}

\author{
Catarina S. Silva ${ }^{1}$, Gilberto T. Silva², Lília Andrade², Alcina Saraiva² \\ ${ }^{1}$ Serviço de Medicina Interna, ${ }^{2}$ Serviço de Pneumologia, Centro Hospitalar do Baixo Vouga, Aveiro, Portugal.
}

\section{Resumo}

A Síndrome de Erasmus designa a associação entre Esclerose Sistémica e exposição à silica, com ou sem silicose. Não existe nenhuma particularidade clínica, radiológica ou histológica distintiva, além da justaposição sindrómica dos estigmas das duas doenças. A pneumoconiose provocada pela sílica pode evoluir para Esclerose Sistémica. 0 mecanismo parece envolver a resposta inflamatória provocada pela exposição à sílica. Visto ser uma doença potencialmente fatal e não existir um tratamento efetivo, a prevenção primária e reconhecimento precoce são muito importantes. Apresentamos o caso de um doente exposto à sílica que desenvolveu Esclerose Sistémica.

Palavras-chave: Síndrome de Erasmus; esclerose sistémica; exposição à sílica; silicose.

\section{Introdução}

A silicose inclui um espectro de doenças ocupacionais pulmonares causadas pela inalação de partículas livres de sílica por trabalhadores de uma variedade de indústrias, incluindo a construção $0^{1-3}$. A esclerodermia engloba um grupo heterogéneo de doenças relacionadas pela presença de lesões cutâneas espessadas e esclerosadas, podendo ser localizada ou sistémica ${ }^{4}$.

A Síndrome de Erasmus (SE) designa a associação entre Esclerose Sistémica (ES) e exposição à silica, com ou sem silicose. Se presente, a silicose habitualmente precede a esclerose sistémica, não existindo nenhuma particularidade clínica, radiológica ou histológica distintiva, além da justaposição sindrómica dos estigmas das duas doença $a^{5-7}$.

\section{Caso clínico}

Doente do sexo masculino, de 64 anos, trabalhou durante 47 anos como pedreiro, sem uso habitual de proteção individual, estando reformado há dois anos. Não fumador. Fratura de costelas traumática quatro meses antes, complicada com empiema, sem outros antecedentes de relevo e sem medicação crónica.

Recorreu ao serviço de urgência por quadro de dispneia para pequenos esforços, tosse não produtiva e edemas dos membros inferiores. Ao exame objetivo destacava-se apagamento das rugas da face, espessamento cutâneo difuso, incluindo face, tórax anterosuperior e membros superiores (Figura 1). Verificou-se haver Fenómeno de Raynaud. Eupneico em repouso, sem hipoxémia e hemodinamicamente estável. A auscultação pulmonar revelava abolição do murmúrio vesicular no terço inferior direito, sendo o restante exame objectivo normal.

\section{Abstract}

Erasmus Syndrome refers to the association between Systemic Sclerosis and exposure to silica, with or without silicosis. There are no specific clinic, radiologic or histologic findings, except the overlapping symptoms of the two diseases. Pneumoconiosis due to exposure to silica can evolve to Systemic Sclerosis. The mechanism seems to involve the inflammatory response triggered by silica exposure. Since it is potentially lethal and has no effective treatment, the primary prevention and early recognition are very important. We present the case of a patient exposed to silica who developed Systemic Sclerosis.

Key words: Erasmus syndrome; systemic sclerosis; exposure to silica; silicosis.
Figura 1. Apagamento das rugas da face

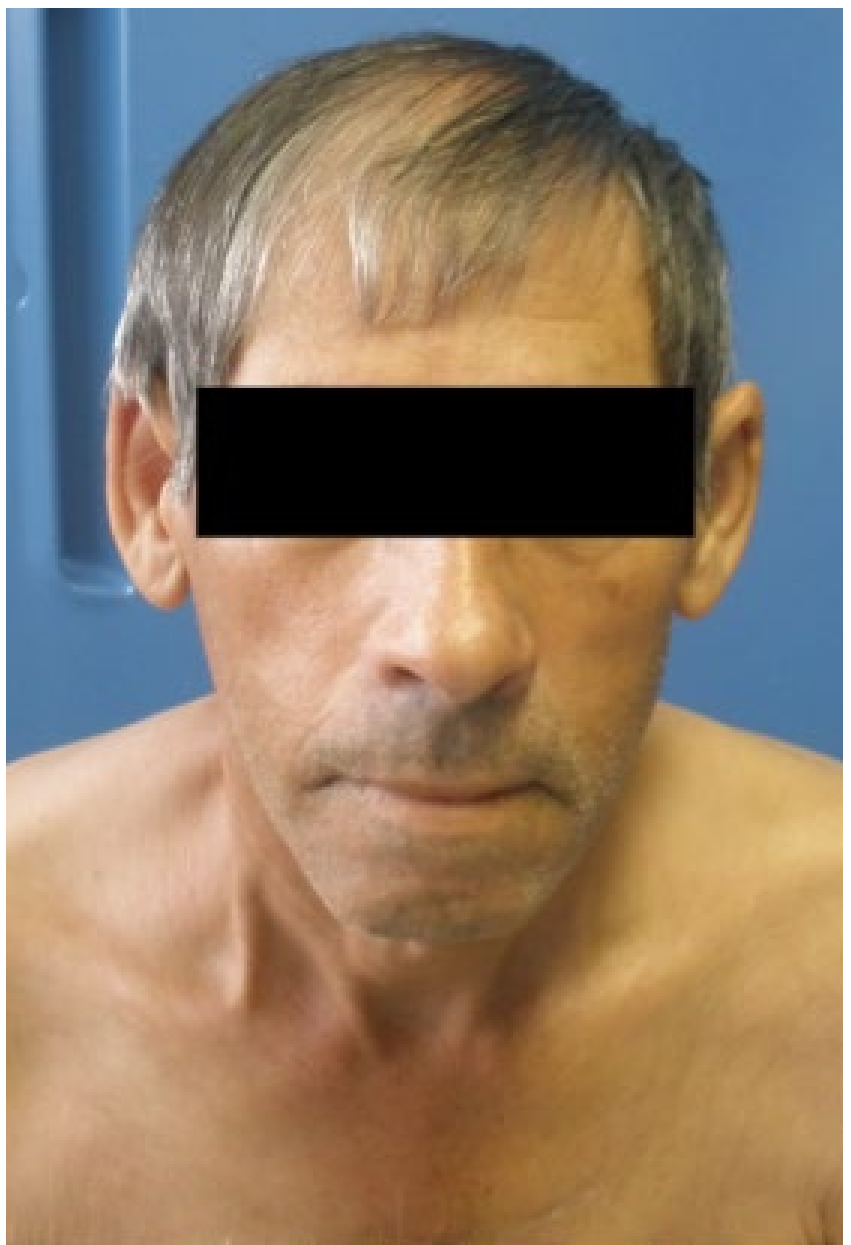


Tabela 1. Resumo de exame realizados.

\begin{tabular}{|llll|}
\hline Analítica de Sangue & Líquido pleural & Broncofibroscopia & $\begin{array}{l}\text { Provas Funcionais Respiratórias } \\
\text { Iniciais/Controlo }\end{array}$ \\
\hline $\begin{array}{l}\mathrm{Hb}: 10.7 \mathrm{~g} / \mathrm{dl} \\
\text { (normocítica normocrómica) }\end{array}$ & Amarelo citrino & $\begin{array}{l}\text { Sinais inflamatórios da mucosa (grau } \\
\text { II) com pigmentos de antracose }\end{array}$ & CVF 63\%/ 48,4\% \\
Bioquímica: normal & $\begin{array}{l}\text { Celularidade }>1000 / \mathrm{mm}^{3}, \\
\text { predomínio de polimorfonuclear }\end{array}$ & $\begin{array}{l}\text { Aspirado brônquico: citologia e } \\
\text { bacteriologia normais }\end{array}$ & FVE1 $67,8 \% / 53,7 \%$ \\
VS: $80 \mathrm{~mm} / \mathrm{h}$ & $\begin{array}{l}\text { Citologia negativa para células } \\
\text { malignas }\end{array}$ & Lavado broncoalveolar inespecífico & DLCO 31,7\%/25,8\% \\
Ac anti-Scl70 $>320 \mathrm{U} / \mathrm{L}$ (positivo) & $\begin{array}{l}\text { Pesquisa de BK directo, cultural e } \\
\text { por PCR negativos }\end{array}$ & $\begin{array}{l}\text { Biópsia negativa para células } \\
\text { malignas e para BK }\end{array}$ & \\
Gasimetria em ar ambiente: normal & & & \\
\hline
\end{tabular}

CVF capacidade vital forçada, DLCO difusão alvéolo-capilar de CO, FVE1 volume expiratório máximo num segundo, PCR polimerase chain reaction, VS velocidade de sedimentação

Analiticamente, destacava-se anemia normocítica normocrómica, velocidade de sedimentação elevada e anticorpo anti-Scl70 positivo; A gasimetria arterial era normal (Tabela 1).

A radiografia de tórax revelou opacidade do terço inferior direito sugestiva de derrame pleural e sinais de fratura de cinco costelas direitas. A TAC torácica de alta resolução mostrou cardiomegalia, moderado derrame pericárdico, ligeiro derrame pleural bilateral, áreas de consolidação com broncograma nos segmentos inferiores, reticulite difusa dos vértices às bases, micronodulação difusa centrilobular, pequenos nódulos subpleurais e vários maiores, calcificados, com predomínio no hemitórax direito (Figura 2).

Realizada toracocentese para estudo bioquímico, citológico e microbiológico do líquido pleural que mostrou aumento do número de leucócitos polimorfonucleares. A broncofibroscopia evidenciou inflamação da mucosa e pigmentos de antracose. 0 aspirado brônquico, lavado broncoalveolar e biopsia não revelaram alterações. As provas funcionais respiratórias objetivaram síndrome restritiva ligeira, com agravamento significativo nos dois meses seguintes (Tabela 1). 0 ecocardiograma inicial mostrou disfunção diastólica do ventrículo esquerdo, insuficiência tricúspide ligeira e pequeno derrame pericárdico. Dois meses depois eram já visíveis sinais indiretos de hipertensão pulmonar e derrame pericárdico significativos, não tendo sido realizada pericardiocentese por ser ter sido considerada de elevado risco.

Inicialmente, foi realizado tratamento sintomático, que incluiu pentoxifilina 400mg 3id, nifedipina 20 mg id e naproxeno 500 mg 2id para

Figura 2. TAC toracica em janela de parenquima destacando-se derrame pleural e pericardico e reticulite difusa

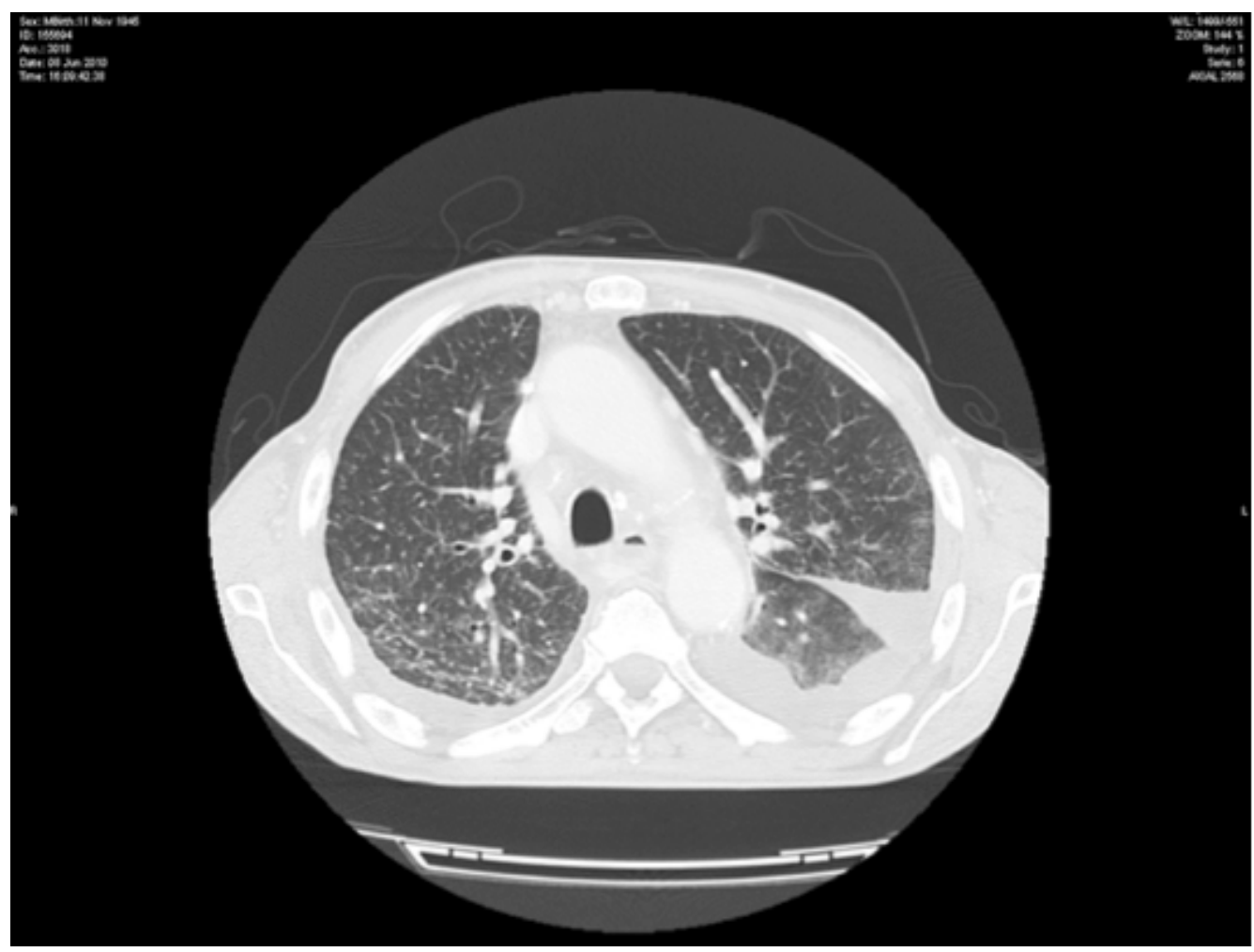


o Fenómeno de Raynaud, e foi iniciada cinesiterapia. Registou-se uma melhoria clínica e o doente passou a ser seguido em consultas externas. Apesar dos exames subsequentes mostrarem evolução rápida da doença, não houve agravamento sintomático significativo durante os três meses seguintes. Desenvolveu então crise renal esclerodérmica, acabando por falecer nesse contexto.

\section{Discussão}

A ES subdivide-se em ES cutânea difusa (ESCD), ES cutânea limitada e ES sine scleroderma, dependendo da extensão do atingimento cutâneo e do padrão de envolvimento de órgãos internos 8 . 0 prognóstico é variável, tendo o subtipo ESCD uma baixa taxa de sobrevivência 6 .

A citotoxicidade da silica cristalina parece atuar diretamente sobre o sistema imunitário, sendo o seu alvo privilegiado os macrófagos, que induzem morte celular, com libertação de citoquinas, em particular interleucina-1 e fator de necrose tumoral gama ${ }^{9}$, o que favorece quer a inflamação e fibrose de células pulmonares, quer a eclosão de uma doença autoimune como a esclerodermia ${ }^{10,11}$.

A manifestação radiológica pulmonar mais precoce da silicose é a presença de pequenas opacidades nodulares, predominantemente nas zonas superiores, associadas a adenopatias hilares. Na ES, o padrão mais habitual é a fibrose pulmonar inespecífica com imagens em favo de mel². 0 lavado broncoalveolar tipicamente revela um aumento do número de granulócitos, 0 que indicia alveolite ativa ${ }^{12}$.

Os anticorpos antinucleares (ANA) podem ser úteis para "screening" de ES. Os antitopoisomerase (anti-Scl-70), anticentrómero (ACA), anti-RNA polimerasa III e anti beta2-glicoproteina são muito específicos ${ }^{13}$. 0 ACA é específico de ESCL e 0 anti-Scl-70 está associada a ESCD e a um risco mais elevado de doença pulmonar intersticial grave ${ }^{14}$.

Não existe atualmente um tratamento específico da ES ou da silicose, além do sintomático. A combinação de glucocorticoódes e agentes imunossupressores pode ser usada na ES mas apenas se houver sinais de alveolite ativa ${ }^{15}$. 0 uso de glucocorticóides parece relacionar-se com o desenvolvimento de crise renal, uma complicação rara mas potencialmente fatal da $E S^{16}$.

Foi feito, neste caso, o diagnóstico de SE num doente com história de exposição prolongada à sílica. A presença de micronodulação nodular pulmonar difusa sugere a presença de silicose. A extensão das lesões cutâneas e 0 atingimento de sistémico estão de acordo com o subtipo ESCD, confirmado pela positividade do anticorpo Scl-70. Não houve evidência de alveolite ativa nos exames complementares realizados e, numa fase inicial, o tratamento sintomático foi eficaz, pelo que o potencial benefício do uso de glucocorticóides ou imunosupressores não estaria indicado. Apesar disso, o doente desenvolveu crise renal esclerodérmica, o que poderá deverse à rapidez com que a doença se desenvolveu, indiciando a sua gravidade.

Salienta-se a importância da prevenção primária das doenças associadas à exposição à sílica, através da sensibilização para 0 uso de material de protecção respiratória adequado e notificação dos casos detetados.

\section{Bibliografia}

1. Mridu Gulati \& Carrie A. Redlich. Fishman's pulmonary diseases and disorders Section Eleven. Occupational Disorders

2. McCormic ZD, Khuder SS, Aryal BK, Ames AL, Khuder SA. Occupational silica exposure as a risk factor for scleroderma: a meta-analysis. Int Arch Occup Environ Health. 2010 0ct; 83 (7):763-9.

3. Valiante DJ, Schill DP, Rosenman KD. Highway repair: a new silicosis threat. Socie E. Am J Public Health. 2004; 94 (5):876.

4. Black CM, Scleroderma-clinical aspects. Scleroderma (systemic sclerosis): classification, subsets and pathogenesis. J Intern Med. 1993; 234 (2):115.

5. Devulder B, Plouvier B, Martin JC, Lenoir L. The association: scleroderma-silicosis or Erasmus' syndrome. Nouv Presse Med. 1977; 6 (32):2877-9.

6. Silman AJ, Scleroderma. Baillieres Clin Rheumatol. 1995; 9 (3):471.

7. Rustin MH, Bull HA, Ziegler V, Mehlhorn J, Haustein UF, Maddison PJ, James J, Dowd PM. Silica-aasociates systemic sclerosis is clinically, serologically and immunologically indistinguishable from idiopathic system sclerosis. Br J Dermatol. 1990 Dec; 123 (6):725-34.

8. LeRoy EC, Black C, Fleischmajer R, Jablonska S, Krieg T, Medsger TA Jr, Rowell N, Wollheim F. Scleroderma (systemic sclerosis): classification, subsets and pathogenesis. J Rheumatol. 1988; 15 (2):202.

9. Koeger AC, Marre JP, Rozenberg S, Gutmann L, Bourgeois P. Maladies auto-immunes après exposition inhabituelle à la silice ou aux silicones. Trois observations. Ann Intern Med 1992; 143:165-70.

10. Rimal B, Greenberg AK, Rom WN. Basic pathogenetic mechanisms in silicosis: Current understanding. Curr Opin Pulm Med. 2005; 11 (2):169.

11. H. Ajlani, N. Meddeb, H. Sahli, S. Sellami. Syndrome d'Erasmus: à propos d'une observation. Revue de Pneumologie clinique. 2009; 65:16-22.

12. Harrison NK, Glanville AR, Strickland B, Haslam PL, Corrin B, Addis BJ, Lawrence R, Millar AB, Black CM, Turner-Warwick M. Pulmonary involvement in systemic sclerosis: the detection of early changes by thin section CT scan, bronchoalveolar lavage and 99mTc-DTPA clearance. Respir Med. 1989; 83 (5):403-14

13. Reveille JD, Solomon DH, American College of Rheumatology Ad Hoc Committee of Immunologic Testing Guidelines. Evidence-based guidelines for the use of immunologic tests: anticentromere, Scl-70, and nucleolar antibodies.Arthritis Rheum. 2003; 49 (3):399.

14. Hu PQ, Fertig N, Medsger TA Jr, Wright TM. Correlation of serum anti-DNA topoisomerase I antibody levels with disease severity and activity in systemic sclerosis. Arthritis Rheum. 2003; 48 (5):1363.

15. Hoyles RK, Ellis RW, Wellsbury J, et al. A multicenter, pros- pective, randomized double blind, placebo-controlled trial of corticosteroids and intravenous cyclophosphamide followed by oral azathioprine for the treatment of pulmonary fibrosis in scleroderma. Arthritis Rheum 2006; 54:3962-70.

16. Luc Mouthon, Alice Bérezné, Guillaume Bussone, Laure-Hélène Noël, Peter M. Villiger, Loïc Guillevin. Scleroderma renal crisis: a rare but severe complication of systemic sclerosis. Clinical Reviews in Allergy \& Immunology. 2011; 40 (2):84-91. 